\title{
Knowledge co-production in protective spaces: case studies of two climate adaptation projects
}

\author{
Wouter P. C. Boon ${ }^{1}$ (D) - Laurens K. Hessels ${ }^{2,3}$ • Edwin Horlings ${ }^{4}$
}

Received: 19 July 2017 / Accepted: 8 May 2019 / Published online: 14 June 2019

(C) The Author(s) 2019

\begin{abstract}
Knowledge co-production, a mode of research including contributions both from academic and non-academic actors, is a promising approach for climate adaptation research in order to produce knowledge that supports the development of local and regional adaptation policies. However, such a local and practical focus may be ill-aligned with the global ambitions of academic participants. The differences between performance criteria of academic and non-academic partners make knowledge coproduction unlikely to emerge and survive without protection. This paper aims to understand how different participants in knowledge co-production for climate adaptation can be protected from the norms, values, and performance criteria of their own respective organizations and communities. We found that combinations of shielding (moderating pressures from the selection environment), nurturing (supporting knowledge development), and empowerment (increasing influence over the contexts) activities lead to more successful knowledge co-production. Moreover, our analysis shows that there is no silver bullet for the protection of knowledge co-production. An effective protection strategy should be tailored to the research problem and the social network of a given program.
\end{abstract}

Keywords Climate adaptation $\cdot$ Knowledge co-production $\cdot$ Transdisciplinarity $\cdot$ Protective spaces

\section{Introduction}

There is a wide consensus that producing solutions for multisided and imminent problems call for a form of knowledge production including contributions from both scientific and societal actors (Hirsch Hadorn et al. 2008; Nowotny et al.

Editor: Tony Weir

Electronic supplementary material The online version of this article (https://doi.org/10.1007/s10113-019-01517-4) contains supplementary material, which is available to authorized users.

Wouter P. C. Boon

w.p.c.boon@uu.nl

1 Innovation Studies, Copernicus Institute of Sustainable Development, Utrecht University, Heidelberglaan 2, 3584 CS Utrecht, The Netherlands

2 KWR Watercycle Research Institute, Postbus 1072, 3430 BB Nieuwegein, The Netherlands

3 Centre for Science and Technology Studies (CWTS), Leiden University, P.O. Box 905, 2300 AX Leiden, The Netherlands

4 Centraal Bureau voor de Statistiek, Postbus 24500, 2490 HA Den Haag, The Netherlands
2001; Rosenfield 1992). Also in the domain of climate adaptation, knowledge co-production has a great potential to address salient questions of stakeholders and decision-makers (Bisaro et al. 2016; Moss et al. 2013). Climate adaptation projects are multi-sided and require the integration of inputs from multiple disciplines and practices (Hegger et al. 2012a, b; Klenk and Meehan 2015; Runhaar et al. 2016). Moreover, because of the imminent nature of climate problems, adaptation research needs to be solution-oriented (Hinkel and Bisaro 2016; Kates 2011).

The key characteristic of knowledge co-production is the involvement of non-academics (Hegger et al. 2012a, b; McNie 2007; Pohl et al. 2010). Knowledge co-production involves collaboration among a wide array of actors, ranging from traditional knowledge producers - academic and non-academic - to companies, regulators, users, and special interest groups, in all stages of research (de Jong et al. 2016; Rosenfield 1992). It combines formal scientific knowledge with local experiential knowledge and demands, which is assumed to increase societal robustness of knowledge production (Boon et al. 2011).

Knowledge co-production, also referred to as transdisciplinary research or joint knowledge production, is unlikely to emerge and survive without intervention. The growing 
literature on knowledge co-production and transdisciplinarity highlights methodological, epistemological, social, political, and institutional barriers (Brouwer et al. 2018). The challenges of collaborating between researchers and nonacademic stakeholders relate to organizational and institutional differences. Scientists and stakeholders have different kinds of knowledge and their knowledge requirements, timeframes, and expectations of research may not match well (Choi et al. 2004; Kloet et al. 2013; Lemos et al. 2012). Their organizations expect a short-term return on investments and are averse to uncertainty and risk of failure (e.g., Brownson et al. 2006; Choi et al. 2004). Related, the incentives governing scientists and stakeholders are misaligned. Communities of peers that control access to journals, conferences, and scientific careers generally expect global significance, whereas stakeholders require local and contextualized solutions to short-term problems (Scholz and Steiner 2015). Climate adaptation research projects primarily aim for outcomes that can be directly used for solving local problems (Hegger et al. 2012a, b; Runhaar et al. 2012). This mismatch creates difficulties in initiating and organizing knowledge co-production projects (Boon et al. 2014a).

Creating the right conditions to facilitate effective knowledge co-production is thus a major challenge for climate adaptation and environmental program managers (de Jong et al. 2016; Rosenlund et al. 2016). One way to encourage knowledge co-production is by locating it in a protective space, i.e., a niche in which knowledge or innovations can be pursued insulated from the pressures of the prevailing regime. Being insulated from the prevailing regime would imply that academic and non-academic participants are sheltered from the norms, values, and performance criteria of their own respective organizations and communities. This allows the agendas of individual scientists and research groups to deviate markedly from the priorities of their home discipline. One of these deviations is to allow for a different orientation towards societal relevance. Protection also gives civil servants, company staff, and employees of other non-academic organizations room to be involved in activities outside their formal task description.

The phenomenon of protective spaces has been addressed in relation to technological development in the literature on strategic niche management (Kemp et al. 1998; Schot and Geels 2008). There, novel technologies are developed in niches that are shielded from the prevailing socio-technical regime. This strand of literature found that innovations that are not ready to compete with dominant, incumbent technologies particularly require protection (Raven 2005; Ulmanen et al. 2009). With this paper, we aim to contribute to the understanding of protective spaces in knowledge co-production by exploring to what extent the protection measures found in strategic niche management literature are applicable to knowledge co-production. By focusing on the central issue of how protection can help organizing successful knowledge co-production, this paper chooses a normative rather than descriptive "lens" on knowledge co-production (Bremer and Meisch 2017). Rather than diagnosing problems at the sciencesociety interface, we contribute to the development of effective modes for interfacing science and society. The leading research question is: what (combinations of) protection measures can successfully facilitate knowledge co-production?

\section{Theoretical framework}

In this section, we develop a theoretical framework for understanding what happens in knowledge co-production projects in terms of protection.

\section{Protecting knowledge co-production}

In knowledge co-production, societal stakeholders-such as civil servants, citizens, and employees of firms - and scientists are together on a common problem, developing shared concepts, skills, and goals. In the literature on science policy and science-society relationships, knowledge co-production is often discussed under the broader term transdisciplinary research, alongside with its other key aspect interdisciplinary integration (Choi and Pak 2006; Rosenfield 1992). For the sake of clarity, we will use the term knowledge coproduction throughout this paper, but we will also build on the transdisciplinarity literature.

The participation of societal actors in knowledge production means that their epistemic perspectives and their experiential and local knowledge have to be integrated with formal scientific knowledge (Brugnach 2017). This knowledge integration is difficult and the end-results are not always regarded as legitimate by scientific journals and research councils (Lauto and Sengoku 2015; Lyall et al. 2015).

Apart from this epistemic challenge, the wide range of actors participating in knowledge co-production involves a diverse set of motivations, expectations, and incentive systems (Scholz and Steiner 2015). Scientists typically gain reputation by publishing their findings in journals or academic books (Whitley 2000). Their incentives are to generate insights that provide input for scientific publications. Intensive collaboration with non-academic actors may require to focus on issues with high practical relevance in a local or regional context, which are not necessarily relevant for academic debates.

The role of societal actors changes from knowledge users to co-producers of knowledge. Their incentives are to acquire concrete information as input for short-term activities, for longer-term visioning, for strategic purposes, or for a demand articulation exercise to investigate what could be important to know. Societal actors, however, are rarely evaluated by their 
principals based on their knowledge products, which makes it hard to align incentives (Kloet et al. 2013; Zscheischler et al. 2017).

Scientists and stakeholders may each have intrinsic and extrinsic motivations to co-produce knowledge in niches or protective spaces, but these motivations are not the same. To reconcile these differences and keep project participants motivated and incentivized, measures are needed to protect knowledge co-production projects.

\section{Protection measures: shielding, nurturing, and empowering}

Our conceptualization of the protection of knowledge coproduction is inspired by the concept of protective spaces from the strategic niche management literature. This approach has its origins in evolutionary economics (Nelson and Winter 1982) and proposes that protection may be needed for radical innovations to develop before they are subjected to the harsh reality of the selection environment. Protective spaces or niches function as "proto-markets" that support experimentation with the technology's characteristics as well as its related infrastructure, user practices, and other environmental conditions (Schot and Geels 2008). This helps new technologies survive in a competitive environment dominated by incumbent technologies.

This paper aims to explore to what extent the notion of protective spaces is useful in the context of knowledge coproduction practices, e.g., to survive in the competitive academic environment dominated by scientific journals and other institutions from established disciplines. The application of the concept of protective spaces to knowledge co-production raises questions about (1) how protection is arranged and (2) how knowledge co-production in these spaces gains legitimacy vis-à-vis other contexts.

Building on strategic niche management literature, we take three processes that might contribute to protection as a starting point of our exploration: shielding, nurturing, and empowering. The literature initially focused on two key processes that contribute to niche protection: shielding and nurturing. Shielding is an outward-oriented activity, aimed at moderating or fencing off pressures presented by the selection environment, thus providing room for experimentation. Shielding can take an active form, when the protective space is created, or a passive form, when the space coincides with a pre-existing and low-profile setting (Smith et al. 2013). Nurturing refers to processes that support development of the technology inside the niche. Three processes are seen as significant in nurturing: stimulating learning processes, articulating expectations, and building networks (Kemp et al. 1998).

Niches are dependent on the expectations and visions of actors inside as well as outside the niche. The constellation of expectations and visions shapes narratives about the reasons for the existence of the niche (Boon et al. 2014b; Smith and Raven 2012). In this vein, Smith and Raven (2012) have introduced empowering as the third key process. Empowering is an outward-oriented activity aimed at increasing the credibility and legitimacy of the niche itself and the influence of the niche over its contexts. Empowering touches on competition as well, because narratives can provoke anti-narratives and lead to contestations and tensions.

\section{Success of knowledge co-production}

Success of knowledge co-production projects can be measured using a wide range of dimensions. Traditionally, organizational and science studies use effectiveness, i.e., the degree of goal attainment, as a measure for project success (Cooke-Davies 2002; de Wit 1988). Complementary to effectiveness, satisfaction has been used as a way to add the evaluation of the experience of the process that project participants went through (Kenis and Provan 2009; Provan and Milward 1999).

Next to these two internal-oriented success measures, we include an outward-oriented dimension. First, we include a formal assessment of the project by external reviewers. Second, we take knowledge utilization: participants aspire to communicate lessons learned in knowledge co-production projects to various knowledge users outside the project.

One can distinguish between several layers in the project environment that represent different knowledge users. The first and inner circle consists of the organizations to which the niche participants belong. These so-called "home organizations" can benefit from the products of the team and are expected to have an interest. This initial interest pertains to the fact that teams and projects are decoupled from businessas-usual practices (Aldrich 1979) and have been given room for flexible and innovative thinking. However, transfer between team members and their home organizations can be hampered by "learning boundaries" (Scarbrough 2004).

The second circle consists of the professional networks of the team members. These networks may be called communities of practice (Wenger 1998) or knowledge value collectives (Bozeman and Rogers 2002) and refer to loosely linked groups of people that share the same socio-cognitive repertoire. This repertoire includes the reservoir from which community members draw their knowledge and the theories, methodologies, instruments, and codes of conduct that have become common in the community. The socio-cognitive repertoire functions as a guide and fuels the evaluation criteria and routines in a community (Constant 1987; Garud and Rappa 1994).

Last, continuation in new projects, the sustainability of relations and networks is considered. In sum, both internal (effectiveness and satisfaction) and external (formal evaluation, 
knowledge utilization in home organizations and beyond, and continuation) measures are indications of the extent to which knowledge experimentation in protected settings offered outcomes that are perceived as useful and legitimate by others.

\section{Data and methods}

\section{Case selection}

We study knowledge co-production in teams within the Knowledge for Climate research program (CfK) that ran from 2008 to 2014 in the Netherlands. CfK is a large-scale program that concentrates on climate adaptation research. The program involves a wide range of actors and focuses on local and regional projects with the idea that adaptation measures become relevant on these levels. A major part of the program is delegated to nine so-called "hotspots." Some of these hotspots are locally concentrated, such as the port of Rotterdam and Schiphol Airport. Other hotspots are more thematically formulated, such as those focusing on "dry rural areas" and "shallow waters and peat meadow areas."

Committees consisting of stakeholders, such as municipalities, water boards, regional authorities, and companies, govern the hotspots. The CfK program is divided into three tranches that should ultimately form input for drafting a regional adaptation strategy. The idea behind the hotspots is that knowledge is developed as part of a co-production process of scientists, other knowledge agents, and societal partners. An important ambition of the program is that the knowledge produced is more readily included in policy making and implementation.

We assume the hotspot projects of the CfK program to be protective niches. The hotspots are knowledge co-production projects in mission and design. They bring together actors from different backgrounds and sectors as equal partners to co-produce practical solutions for local problems based on an integration of multidisciplinary scientific and experiential knowledge. Such consortia would not typically emerge without some form of institutional and financial support as is the integrated knowledge they produce. The hotspots are formally located in the CfK program, which can offer protection by providing resources as well as an institutionally neutral environment.

In this paper, we make an in-depth study of two such hotspot projects: a project on the urban heat island effect and a project on flood risks in unembanked areas. Our analysis focused on knowledge co-production projects in the Rotterdam hotspot because Rotterdam supported the widest and therefore richest range of projects. The Rotterdam hotspot supported nine projects in total. To explore protection dynamics in these projects, and to develop a theoretical framework to better understand protection in knowledge co-production projects, we selected two projects. The explorative nature of our research invites for selecting cases based on a theoretical replication logic (Yin 2009), i.e., search for different outcomes as a result of predictable characteristics. In the case of knowledge co-production projects, previous scholars have drawn the attention to project characteristics that influence project success, covering contextual, institutional, intra-team, and personal factors (Boon et al. 2014a; Stokols et al. 2008). Since protection concerns the position of a research project in a wider environment, we wanted to differentiate the cases in terms of a priori establishment and legitimacy, and the degree of ambition. Therefore, ex-ante social proximity and cognitive uncertainty were chosen to contrast the cases. The urban heat case, on the one hand, concerns the convergence of researchers from different disciplines that had not worked with each other (low social proximity) on a topic that was scientifically novel (high cognitive uncertainty). The flood risk project, on the other hand, builds on previous projects in the sense that the participants had already worked with each other (high social proximity), using an established research methodology (low cognitive uncertainty).

\section{Methods}

We have used a qualitative approach based on document analysis and in-depth interviews. These methods are described in detail below.

The main purpose of the document analysis was to obtain an overview of the context and content of the projects. This approach uncovered the codified knowledge of the project which could be used to map the most significant events and outcomes of the project on a timeline, adding to the timeline that was drafted during the interviews. The documents were obtained from the project website and replenished with documents provided by the $\mathrm{CfK}$ program bureau and the interview respondents.

The exploration of the main concepts introduced in the previous section, protection measures and project success, were then measured through in-depth interviews. The selection of interview respondents was made using the CfK program's project database, which provides details of all participating persons. We only selected persons who were involved substantively, thus excluding financial administrators and legal representatives. The remaining persons were approached, making sure that at least one person of every participating organization was represented in the sample. Also, we tried to reach a proper balance between senior and junior participants, as well as academic and non-academic researchers. Table 1 in the Appendix (online supplement) presents the composition of the sample, showing that we obtained a near-complete coverage of organizations involved in the two projects.

The interviews had an average length of $75 \mathrm{~min}$ and were audio-taped and transcribed. The transcripts were sent to the 
interviewees for verification. The interview protocol consisted of open questions based on indicators. Table 1 presents an analytical framework that follows from the conceptualization presented in the "Theoretical framework" section and assists in exploring what protection measures ("protection measures" in Table 1) can successfully facilitate knowledge coproduction ("project success"). We broke interview and document data down in component parts that were subsequently grouped into categories; the indicators of Table 1 served as a starting point for the categories. By "grouping the data" around the indicators, we were able to distinguish patterns for each variable, which we present in the following section. Given the different background of the interview respondents, their perspectives on the object of study and their statements were quite diverse, making frequencies of incidents less insightful than capturing the diverse range of insights. At the same time, in the cases that multiple respondents (dis) agreed on a variable, this has carried more weight in our analysis. Because of the interpretative nature of the coding and grouping work, they were carried out by two independent researchers who compared and discussed the analysis. We included references to accounts of interview respondents (R), several interview respondents (SR), and documents (D). A selection of illustrative quotes that support the findings are included in Table 2 and Table 3 in the Appendix (online supplement), and referred to as R1 ... R41 in the text.

\section{Results}

\section{Case 1: the urban heat island effect}

Urban heat island (UHI) is the phenomenon that city areas are warmer than their surrounding areas, which may have repercussions for health and well-being, creating so-called heat stress. In 2003, a heat wave caused a large number of deaths in Europe forcing the health effects of heat onto the research agenda. Urban heat featured prominently in the Fourth

Table 1 Analytical framework and operationalization of protection measures and project success science niches

\begin{tabular}{|c|c|c|c|}
\hline Aspects & Dimensions & Indicators & Examples \\
\hline \multirow[t]{7}{*}{$\begin{array}{l}\text { Protection } \\
\text { measures }\end{array}$} & $\begin{array}{l}\text { Shielding (active): activities to moderate } \\
\text { or fence off pressures presented by } \\
\text { the selection environment, thus } \\
\text { providing room for experimentation }\end{array}$ & $\begin{array}{l}\text { Introduction of measures } \\
\text { (financial, conditional regulations) } \\
\text { to create protective space }\end{array}$ & $\begin{array}{l}\text { Subsidies, co-funding rules, } \\
\text { requirements about variety } \\
\text { of stakeholders involved }\end{array}$ \\
\hline & $\begin{array}{l}\text { Shielding (passive): protection from } \\
\text { selection environment coincides } \\
\text { with a pre-existing and low-profile } \\
\text { setting }\end{array}$ & $\begin{array}{l}\text { Pre-existing, low-profile and/or } \\
\text { inferior setting that signals special status }\end{array}$ & $\begin{array}{l}\text { Already available data from } \\
\text { earlier (student) project }\end{array}$ \\
\hline & \multirow[t]{3}{*}{$\begin{array}{l}\text { Nurturing: processes that support } \\
\text { development inside the project }\end{array}$} & Stimulating learning processes & $\begin{array}{l}\text { Stimulating to talk in same } \\
\text { language and use same set } \\
\text { of concepts }\end{array}$ \\
\hline & & Articulating of expectations & $\begin{array}{l}\text { Visions and objectives as } \\
\text { expressed in the project } \\
\text { proposal }\end{array}$ \\
\hline & & Building networks & Starting new collaborations \\
\hline & \multirow[t]{2}{*}{$\begin{array}{l}\text { Empowering: activities to increase } \\
\text { credibility and legitimacy of the } \\
\text { project }\end{array}$} & Gaining credibility and legitimization & $\begin{array}{l}\text { Statements of stakeholders } \\
\text { outside the project } \\
\text { recognizing the value of } \\
\text { the project }\end{array}$ \\
\hline & & $\begin{array}{l}\text { Visioning, narrative building, } \\
\text { relate to antagonistic voices }\end{array}$ & $\begin{array}{l}\text { Statements of project members } \\
\text { about how they explain the } \\
\text { importance of the project }\end{array}$ \\
\hline \multirow[t]{6}{*}{ Project success } & Effectiveness & Objective assessment of goal attainment & $\begin{array}{l}\text { Did the project meet the objectives } \\
\text { as set at the start? }\end{array}$ \\
\hline & Satisfaction & Perception of project participants & $\begin{array}{l}\text { Assessment of the process by } \\
\text { the project participants }\end{array}$ \\
\hline & \multirow[t]{4}{*}{ External evaluation of usability } & $\begin{array}{l}\text { Formal assessment of project by } \\
\text { external reviewers }\end{array}$ & Scores given by external reviewers \\
\hline & & Use of knowledge in home organizations & $\begin{array}{l}\text { Do colleagues in home organization } \\
\text { recognize and use project knowledge? }\end{array}$ \\
\hline & & Use of knowledge in communities of practice & $\begin{array}{l}\text { Do other municipalities want to } \\
\text { use knowledge and expertise? }\end{array}$ \\
\hline & & Sustainability of relations and networks & Continuation in new projects \\
\hline
\end{tabular}


Assessment Report (sub-report on Climate Change 2007: Impacts, Adaptation, and Vulnerability, chapter 8 on Human health) of the Intergovernmental Panel on Climate Change (IPCC) spurring further attention for the topic.

In the Netherlands, the UHI effect and its impact on health and well-being were put on the agenda in Climate changes Spatial Planning, the large-scale research program that preceded CfK. In 2007, the program commissioned a literature review about knowledge and knowledge deficiencies regarding heat stress in Dutch cities. The literature review was quite extensive in its description of causes, consequences, and possible mitigation measures. The review also articulated the lack of attention for the subject in the Netherlands. This literature review, the IPCC report, the heat waves and growing recognition for the link between climate change and health led to the subject being introduced on the research agenda with which the CfK program kicked off in 2008 (D; R).

The Rotterdam hotspot was especially interested in a definition study that would, for the first time since 1975, include heat measurements rather than prediction models. The project ran for over 2 years and had the largest budget of the CfK's first tranche (600,000 euros). The project involved a team of knowledge producers and users including participants from the municipality, three university groups, a public-private knowledge institute, a consultancy firm, and a water knowledge institute. The CfK program financed half the budget; the participants provided the other half.

Following the research question and the analytical framework (Table 1), we discuss the protection measures as well as the degree of successful knowledge co-production.

\section{Protection measures}

Due to the co-production nature of the project, it was expected that more time was needed for interactions, which served as a rationale for protection. In addition, some participants had difficulty selling the idea of investigating UHI in their own organization. Third, resources were needed to secure expensive measurement tools that could otherwise not have been bought.

Shielding was active: there was no pre-existing network or earlier project to build on and the topic was new to Dutch science and policy. The CfK program helped create a "safe haven" for UHI research. Shielding involved repackaging of the research topic in terms consistent with organizational terminology as well as providing non-financial resources such as permits and project management (D). At the same time, the process of shielding was not flawless. The provision of resources produced unrest. A university department left because it thought others were free-riding, while a knowledge institute managed to bully its way in, because that "respectable player" advanced a perspective to the project that program management was unable to ignore (R1). Notwithstanding the collaborative design, there remained an undercurrent of competition within the project: working in these teams does not necessarily decrease the risk or the fear that "others take your ideas" (R2).

Nurturing mainly involved network building and learning. The topic was new to the Dutch context as was the waterhealth connection, so the pre-existing network of knowledge producers and users was quite limited (SR). The two scientists and one construction expert who had been engaged in the precursory literature reviews were replaced by meteorology scientists of another university who were new to the subject and, having just returned to academia, were looking for new research lines (R3). Local government also had no experience in the field. The project participants had not interacted before and had to invest in network building. During the first stages of the project, there were frequent formal meetings (once every 3 to 4 months) focused on information exchange (D). Only later did this pattern change to more informal, discussionbased meetings and bilateral contact (R4).

Learning was a continuous process throughout the project as it became evident in three ways: (1) team members started using the same terms, concepts, and definitions (R5); (2) they discovered possibilities to exchange data, models, and methods; and (3) results from one project partner could be used as input for others (SR). Learning processes varied among the project participants. The policymaker initially had no knowledge of the topic and although she caught up, it remained difficult to fully engage and be responsible for the content of the final report (R6). Also for the scientists, UHI was a new topic. The last time measurements had been done in the Netherlands was in 1975. Only after German and English researchers emphasized the opportunities to tailor measurements to Dutch cityscapes, did the Dutch scientists take notice (D). They had to connect to foreign research and needed to devise their own solutions (R7).

The nurturing activities of learning and network building were further impeded in producing the expected integration of knowledge and exchange of data. The scientists involved had more influence on the direction of research, owing to their advantageous cognitive position (R6) and to that, some of them were able to devote all their time to the project $(\mathrm{R})$. Data exchange was hampered when at least one participant was not eager to share data (R8) and participants insisted on using their hobby horse methodologies (R9), which made comparison and compatibility difficult. There was also the persistent sense of competition, caused by unclear agreements on data ownership that made every participant want to be regarded as the (future) expert on UHI (SR). The lack of openness and willingness to collaborate led, despite intervention by top-level managers of the organizations involved, to the final report constituted compartmentalized rather than integrated results (R10). Nonetheless, the competing participants were fully aware that they could not push their 
competitiveness too far, because they knew that they would depend on each other in tendering for future projects (SR).

In terms of empowerment, the narrative demarcating UHI as important to study was not shared by all (SR). Especially some political parties and media considered UHI a "small topic" that would affect people in a limited area and timeframe and that was put on the agenda by a few advocates of the issue who favored quick action (R11; R12). Also vis-à-vis their own organizations, some project participants needed to convince their bosses why they worked on urban heat (R13).

The project participants tried to overcome these pressures by creating a coherent narrative. From the start, they were interested in the possible existence of UHI and they articulated the question marks over impacts on health and well-being (R14). The municipality wanted to know whether the city was hotter than the surrounding areas and what repercussions this had for the health of the city's inhabitants (R). The extra money provided by the CfK program invited research into questions they would otherwise not have had and that would yield quick results that can be shown to the public (R15). Narratives developed as the project proceeded. Important for this was that the measurements showed that UHI actually existed (R). After that, the municipality gave a definitive "go" for the rest of the project (D; R).

\section{Success of knowledge co-production project}

The goals set out at the start of the project were met (SR). Several mobile and static measurement methods produced data on heat and the impact of built environment and water. A tentative link with health data was made and policy recommendations were proposed. The research led to a range of background reports, a main policy report and a policy workshop in which recommendations were discussed (D). So, the project seemed to be effective.

In terms of satisfaction, the expectations of some actors about the project were tempered. The existence of UHI had been proven, but a conclusive causal relationship between urban heat and health effects was not found (D; R). This offered opportunities for further research, which was duly commissioned, but it proved difficult to extract policy implications and straightforward directions related to health from the results (R16). As mentioned above with nurturing, there was some tension during the course of the project about the degree of openness and willingness to collaborate (SR). At the same time, project participants were to some degree proud of their achievements (R17). They saw opportunities to retail their methods and research approach to other contexts.

The external evaluation of usability resulted in mixed results. The formal assessment for internal use in the CfK program was not favorable as the external reviewers considered the final report as neither scientifically satisfactory nor relevant for policy (D). They were not enthusiastic about the scientific depth, while policymakers struggled with the presented levels of uncertainty (R).

The interview respondents expressed that knowledge produced in the project was transferred to and used in the participants' own organizations (SR). The involved consultancies, semi-public research institutes, and academic institutes continued developing these methods and data in-house. UHI was new to the Dutch commercial and academic research "market" and all parties began to see opportunities to valorize the knowledge produced. Project members indicated that the principals in their home organizations valued what they were doing (R18). The academic partners valorized their work by producing publications and connecting with peers, for instance at scientific conferences (D). They aligned to a global community of scientists working on UHI. The various reports produced by the separate team members refer a great deal to international peers and the scientists involved produced papers for journals and international conferences on the booming field of urban climate, as well as by developing social relations and working their way into international author teams (R). A scientist mentioned that "through the publications they at last became part [of the community]" (see also R17). Respondents from non-academic research institutes mentioned publications as a way to gain credibility in the field, although they focused more on media coverage, networking, and forming a community of practice from which future assignments could be obtained (SR). Through such mechanisms, the project's research methods ended up being used in other Dutch cities as well. The project member who represented the municipality had more difficulties in utilizing the knowledge that was produced. The main reason was that, although the existence of UHI in Rotterdam had been confirmed, the lack of evidence for an impact on health and well-being meant that there was less political and policy relevance to follow-up on the results (R). It appeared difficult to diffuse the knowledge to other departments - responsible for healthcare, sustainability, greening, and spatial planning - which wanted more practical information (R19). Two political parties that did not regard environmental issues as a priority denounced the project: "spending 600k and learning that you need to wear airy clothes is ludicrous" (see also R12). This created uncertainty, especially among policymakers who wanted to prevent the responsible alderman from becoming damaged.

At the same time, a more national community of practice emerged that had the ambition to continue working on UHI. The researchers permitted themselves more freedom to deviate from international codes of practice and introduced innovative ways of investigating UHI. For example, they deployed locally specific measurements on bicycles and trams, built a special installation to gauge temperatures directly above water, and utilized measurements from amateur meteorologists (SR). The local, context-specific nature of the knowledge makes the position of the knowledge producer stronger 
relative to potential users, opening up possibilities for servicing wider valorization. Continuity and valorization happened but along two distinct lines, the academic researchers set up a follow-on project in the context of $\mathrm{CfK}$, whereas research institutes and consultancies created projects for several individual municipalities (D; SR).

In sum, the project was effective in reaching its goals, and satisfactory to particular participants, especially those that were able to valorize the results to the global scientific community or to other local contexts.

\section{Case 2: flood risks in unembanked areas}

Little was known about flood risks of unembanked areas in the Rotterdam area and their consequences and policies were lacking. At the same time, it was understood that climate change, specifically rising sea levels and changes in river discharge, may increase the risk of flooding. Water safety and water management had been on the agenda of the Rotterdam municipality since the 1990s. In 2005, several external events, such as the Al Gore movie "An Inconvenient Truth" and hurricane Katrina, coincided with a large conference during which a vision for the future of Rotterdam was developed. The coinciding developments created an eagerness to propose new policies that linked water management with city development agendas (D; R).

Around the same time, the CfK program approached Rotterdam to participate, creating an opportunity to work together on knowledge development. Demand articulation meetings were organized to prepare for the involvement of Rotterdam in CfK, and it was during one of these meetings that flood risks and external safety in unembanked areas was proposed as a viable research topic $(\mathrm{D} ; \mathrm{R})$.

Like the UHI project, the flood risk team brought together knowledge producers and knowledge users. The project leaders were based at the municipality of Rotterdam and the Rotterdam Port Authority. The other core project partners were a university group, a water knowledge institute, and two consultancy firms. The CfK program provided half the budget, while the participants funded the other half of the project's resources, either in cash or in kind through use of personnel (D).

\section{Protection measures}

Shielding was both active and passive. Active shielding started with the opportunities created by the CfK program to tackle knowledge questions in addition to the questions that arise when making policy: "policymakers have specific questions but do not want new research. However, to answer these [specific] questions, existing knowledge needs to be tailored and contextualized and in some cases even be broadened. CfK creates extra space for such additional research" (R20). The municipality also made funds available for climate adaptation initiatives, but acknowledged that "without CfK the funds for knowledge production would be significantly less" (R21). As all involved parties committed to the project, they "began to think seriously about whether and how to participate" and to look for a good reason to invest in the project. A research institute, for example, stated that they would "only participate when the work is close to what they already are doing" (R22).

Passive shielding entailed articulating the necessity to collaborate on flood risk in unembanked areas. Flood risk was perceived as a multidisciplinary problem and "an innovative solution is only produced by a multidisciplinary approach" (R23). The committee that reviewed the projects suggested that combining the different disciplines would not happen automatically: "the issue should not be easy to solve and there should be some kind of "market failure"" (R). This is why one of the project principals put a lot of effort into involving other knowledge users who might benefit from the project results in addition to the municipality of Rotterdam and the Rotterdam Port Authority (R).

Nurturing of the project was straightforward in terms of network building. The project emerged from an existing network in a close-knit community: "everyone knows each other in the "world of water research"” (R). A downside of this small world is that the water research network is highly "parceled out" (R24). The advantage of a pre-existing network was that the project could have a flying start, which was hampered by two problems. First, the knowledge users who served as the principals of the project were new to the network. This particular problem was assuaged when they took a facilitating role, smoothened the procedures, and quickly learned about water issues (R25). Second, the review procedures and administrative ambiguities of the CfK tendering process severely delayed the start of the project, resulting in one party nearly being unable to take part $(\mathrm{R})$.

The water-related part of the work further developed knowledge and methods produced in earlier projects. This meant that the remaining questions could be assessed beforehand; what kind of knowledge is needed and what the logical follow-up questions would be (R26). Project participants perceived the project being part of a series of projects as an ongoing methodology development (SR). The project had a clear chain of research questions, first characterizing flooding, then modeling flood damage, and finally modeling the vulnerability of the port infrastructure. This "very nice serial connection" (R27) of research questions meant that knowledge development was fueled by intense interactions. The four research partners and the municipality maintained frequent bilateral contacts to co-produce knowledge, exchange data, and discuss starting points (SR). The knowledge users had a special role because they were able to contextualize the results, for example, to determine whether certain flow speeds were realistic given the presence of a breakwater (R28). 
The narrative used to empower the project's participants closely followed the rhetoric behind the Rotterdam municipality's legitimization of its focus on climate adaptation. Water is an integral part of climate adaptation. From a long-term perspective, Rotterdam is vulnerable to rising sea levels and higher river discharge (D). In the last 10 years, there had been inundation problems after heavy rainfall and "every now and then there was a small-scale disaster" (R29), which makes the problem more urgent. The municipality articulated the vision of climate adaptation measures contributing to the social-economic development of the city. The vision promoted living and building houses in attractive but unembanked areas, such as the old harbor, which would make the city more attractive for higher-income people (R). At the same time, since these are "outlaw areas" (R30) where people cannot get insurance, more information on risks is needed.

However, the knowledge users involved in the project were well aware that overstating risks could be problematic. They advised against approaching citizens directly to survey them about risk perceptions (SR). Modeling risks to the port infrastructure was officially done using a fictitious port: "we have flooded a fictitious port, not necessarily the Rotterdam harbor [ ...] basically, a random harbor" (R). This decontextualization was needed because the port authority did not want to raise the suggestion to citizens and (potential) clients, i.e., companies that may want to locate itself in the Rotterdam port, that flood risk and damages were high $(\mathrm{R})$. The sensitivity in communication remained after the project had been completed even though estimated damage levels were not as high as expected. Some of the respondents thought that this led to not "being steered by politics" (R31), but also less impact (R32).

\section{Success of knowledge co-production project}

The project goals were met within time and budget so the project can be regarded as effective (D; SR). In terms of satisfaction, the individuals involved seemed to be eager to participate and were prepared to make sacrifices (R33). This eagerness stemmed from the fact that these organizations saw gaps in knowledge that could be filled and with which money can be made, could work on extending their network, and intrinsic motivations ("we are going to deliver and we do it as well as possible", R34). In a sense, the researchers were cognitively and socially invested in the further development of the models as well as the small intra-organizational group that worked on these issues. The interview respondents coming from knowledge institutes and consultancy claimed to have learned a lot about each other's' methodological approaches (SR). There were minor tensions though, especially regarding the communication of the risk data, and the case of one research organization involved differences in expectations about deliverables (SR). One organization became less interested during the course of the project, because "within my department there is less space for those hobbies" (R35).

Regarding the external evaluation of usability, the external reviewers of the formal assessment of the project were unclear about scientific results of the project. The societal impact of the studies received mixed reviews: as indicated above, one party expected different risk data, whereas other user organizations involved found the simulations insightful, e.g., in terms of urban development questions (D).

In terms of communication to the member's own home organizations, the project team was not only crossing organizational but also project boundaries. Project members made a substantial attempt to integrate methods and data (SR). So, interactive learning was valued and "knowledge should not be kept secret because it ages quickly and disseminating knowledge leads to receiving different knowledge" (R3). The project members representing the knowledge users had mixed experiences with getting the work approved in their own organizations because the results aligned in various degrees with other interests of these organizations (SR). According to one knowledge user, the research "has yielded something that is useful for policy [in] location strategy and spatial planning" (R36): what are vulnerable areas and where should city development be concentrated? Answering policy questions requested a translation exercise, e.g., what do these results mean for the old harbor area? Moreover, the results could be used to flag the importance of the water safety issue in a wider, regional and even national level, and created the opportunity for the knowledge user to become a "lead user" of this kind of research (R37).

The project partners representing research institutes were not so much focused on aggregating their knowledge products to the global level, i.e., to the international scientific community. They were not interested in publishing their results in scientific journals and rather perceived the models they produced as the major end product of the project (SR). Instead of scientific gain, the knowledge producers were interested in transferring their models to other local areas; especially other harbor cities could merit from this knowledge (SR). The respondents regarded such a transferring exercise as complex because the explicit knowledge (e.g., the models) could be easily copied, whereas the implicit knowledge is "something that is exportable" (R38). This means that they suggested to sell their models in combination with consultancy services to contextualize the models to the local needs and circumstances.

The project did not result explicitly in a community of practice but the project partners had been involved in a sequence of projects dealing with a series of evolving research questions. As such, the project can be regarded as part of a continuous learning process, guaranteeing sustainability of relations and networks. In this case, to ensure continuation, the team together communicated the importance of the project (SR). The participants can be regarded as a network that 
actively underlines the importance of their research topic and the fact that they are the best partners to pursue such research (R39). For this, acknowledgment by other stakeholders, most prominently knowledge users, was needed. These users can be influential and have a detrimental effect as well. For example, for one knowledge producer, it was difficult to get a follow-up project, "I suspect, well, that this has to do with the dissatisfaction of [knowledge user] with the results" (R40). To empower their work and network, knowledge producers could attempt to gain access to the decision-making table (R). One knowledge producer had been able to do that in a previous project for the municipality of Dordrecht, but found it slightly disappointing that this interaction was not there in the case of Rotterdam (R41).

All in all, the project is considered successful in terms of attaining the goals, intra-project learning, and continuous network building. Participants could apply the knowledge to a certain extent, whereas there was a moderate outreach beyond the directly involved knowledge users.

\section{Discussion and conclusions}

Knowledge co-production can help climate adaptation research to make a major societal contribution (Bisaro et al. 2016; Moss et al. 2013). The involvement of societal actors - citizens, users, firms, policy makers, special interest groups - as equal partners in a process of knowledge coproduction can help to integrate formal scientific knowledge with local experiential knowledge. Equal partnerships between scientists and societal actors from various sectors do not immediately match with institutional incentives and need some form of intervention to survive. In this paper, we have explored how knowledge co-production works in (potentially) protective spaces. Our main objective is to better understand the factors that contribute to establishing protective spaces in knowledge co-production projects for climate adaptation. To do so, following our analytical framework (Table 1), we have compared protection measures of two knowledge coproduction "hotspot" projects in Knowledge for Climate, a large-scale climate adaptation program in the Netherlands.

\section{Discussion of protection measures and their success}

Both projects have received a certain degree of protection. The UHI project has received a more intensive protection treatment from the CfK program than the flood risk project, especially in terms of nurturing and empowerment. Apparently, however, the stronger protection of the UHI project was insufficient to compensate its challenging starting position, i.e., the high degree of divergence in terms of cognitive uncertainty and social proximity.
Based on assumptions advanced by strategic niche management literature and as summarized in our analytical framework (Table 1), we explored protection as stimulated through three protection measures: shielding, nurturing, and empowering activities.

Shielding, i.e., fencing off pressures from the outside selection environment, created opportunities for asking additional questions and provided access to financial resources, which compensated for the high overhead and meeting costs involved with knowledge co-production projects. The emphasis was on active shielding in case of high cognitive uncertainty and low social proximity (UHI), and on passive shielding where participants could build on earlier projects and strove to continue longstanding research efforts and methodology development (flooding). However, the shielding measures in place could not safeguard the project against opportunistic behavior and private interests, ranging from an undercurrent of competition among participants in the UHI project to quidpro-quo commitment in the flood risk project.

Nurturing, i.e., processes that support development inside the project, received stronger emphasis in the UHI project than in the flood risk project. UHI was a new topic without a network among scientists or policy makers. Given the high cognitive uncertainty and low social proximity, participants had to invest in their relationships and in mutual learning. The flood risk project was a continuation of previous collaborations in a close-knit community of knowledge producers for whom the project was part of their community's work towards a longterm research agenda. This is more in line with the time horizons of scientists and researchers working at knowledge institutes. Knowledge users were new to the flood risk community but voluntarily decided to take on a supporting role. In both projects, nurturing was associated with learning through the development of a shared cognitive repertoire, new data and methods, and alignment of disciplines. However, nurturing activities led to biases in what participants and other stakeholders got out of the projects. Knowledge producers had more influence on the direction at the start of research than knowledge users, and the selection of participants was heavily influenced by vested interests. The pre-existing network of the flood risk project ensured a quick start and established the project's legitimacy, but it may have been too aligned, consensus-driven, and focused on local monopolies.

Regarding empowerment, i.e., activities to increase credibility and legitimacy of the project, the two projects had clear narratives about the local risks and opportunities associated with global climate change, which served to articulate the significance of the project's topic and the need for protection. In both cases throughout the projects, the knowledge users began to shape the narrative and they participated and functioned as champions of the co-production projects. However, participants did not always have the same expectations of the project in which they took part. Results were not always 
relevant for or applicable to use contexts. In the UHI project, this eventually led to a loss of support for the topic when results were too uncertain or unclear for policy. So, the team members were not able to successfully build a project profile.

We have explored whether, and how, two Dutch knowledge co-production projects implicitly incorporated strategies from the "protective spaces" framework (Table 1) in their research design. Our empirical analysis suggests that both Dutch knowledge co-production projects had included protective measures (shielding, nurturing, and empowerment activities); however, they did so differently. The empirical research we presented in the previous section yields three lessons. First, these three protection measures seem to have a beneficial role in overcoming potential disadvantages of knowledge coproduction projects as known in the literature, in particular, a lack of incentives (Scholz and Steiner 2015) and a limited shared knowledge background (Brugnach 2017). Second, the three processes are not working flawlessly, as stakeholders involved sometimes seem to act opportunistically by appropriating results, not being open to other project members, or being susceptible to politics, i.e., concerning questions about what should be protected and for how long. These observations are in line with earlier studies on knowledge coproduction and transdisciplinary projects that found tensions and frictions (Klenk and Meehan 2015; Kloet et al. 2012). Third, the protection measures appear to reinforce each other. For example, shielding and empowerment activities compensated for the absence of a network in the UHI case, and empowerment strategies dictate which kind of shielding activities will be selected. The strong pre-existing network in the flooding case continuously underlined the narrative of why research was needed; at the same time, the narrative increased the cohesion in the network and tried to draw in new actors such as the knowledge users. The reinforcing protection measures are in line with previous research on niche protection (Boon et al. b; Smith and Raven 2012).

\section{Discussion and implications}

This paper shows a first attempt to apply the concept of protection dynamics originating from technology dynamics literature to the field of science studies. This perspective helped us to identify a number of factors that influence protection of knowledge co-production. This is an exploratory paper based on two cases using interviews. To improve the understanding of protected spaces in knowledge co-production, we conducted two in-depth case studies. As such, based on theory, we started from an analytical framework (Table 1) to better understand protection in knowledge co-production projects and used empirical research to refine the model. The limited empirical scope implies that we have to be cautious in extrapolating our findings to other domains or to other national contexts. Moreover, the results show that the two cases are more or less successful in being protected. We did not select cases based on the level of success, as this is a first attempt to investigate protection measures. To be able to study this, we selected cases where we were sure that protection was - more of less - present. This raises the question to what extent and how the protection measures are working in cases of failed projects.

Other limitations that could spur future research are that the success measure can be improved. The current measure focuses on functional outcomes, i.e., reports produced and changes evoked. Although we took satisfactions into account, the success measure would have been more sophisticated if we had assessed perceptions of actors outside the project in a systematic way, and also investigate less explicit impacts of knowledge co-production, such as evolving awareness of problems and shared narrative building.

Our results provide four lessons for managers of climate adaptation programs in which scientists and societal actors coproduce knowledge. First, a silver bullet for the protection of knowledge co-production does not exist. The comparison of the two cases suggests that protection strategies should be even more tailor-made than was the case in CfK. In particular, the urban heat project turned out to require more protection to enable successful knowledge co-production. We recommend that program managers estimate the characteristics of the different projects in their portfolio and design their protection strategy accordingly. Second, in spite of active shielding, private interests and local incentives linger on, resulting either in competition (UHI case) or in a task division between producers and users (flooding case). Third, in line with existing literature and related to the empowering protection measures, we found that scientists and societal actors working on climate adaptation have different expectations of research, different timeframes, and different sensitivities to uncertainty. Developing a vision and narrative around a project or program can foster empowerment towards other actors and create legitimacy, but support for this vision inside the project deserves the attention of policy makers and program managers as well. And finally, expectations and objectives evolve. Changes in the political environment and new research results can change the commitment of participants. This implies that protection strategies cannot be completely designed at the start of a project, but should be updated to address new pressures and challenges in keeping a project legitimate.

Acknowledgments The research project Comparative Monitoring of Knowledge for Climate (project SSA01) is carried out in the framework of the Dutch National Research Programme Knowledge for Climate (www.knowledgeforclimate.org). This research program is co-financed by the Ministry of Infrastructure and the Environment. The researchers were not part of the knowledge co-production projects under study. When carrying out the empirical part of the study the authors worked at the Rathenau Institute. We would like to thank the interview respondents for providing us with information, as well as two anonymous reviewers and Rob Raven for their valuable comments. 
Open Access This article is distributed under the terms of the Creative Commons Attribution 4.0 International License (http:// creativecommons.org/licenses/by/4.0/), which permits unrestricted use, distribution, and reproduction in any medium, provided you give appropriate credit to the original author(s) and the source, provide a link to the Creative Commons license, and indicate if changes were made.

\section{References}

Aldrich HE (1979) Organizations and environments. Prentice Hall, Englewood Cliffs

Bisaro A, Swart R, Hinkel J (2016) Frontiers of solution-oriented adaptation research. Reg Environ Chang 16(1). Springer Berlin Heidelberg):123-136. https://doi.org/10.1007/s10113-015-0766-5

Boon WPC, Moors EHM, Kuhlmann S, Smits REHM (2011) Demand articulation in emerging technologies: intermediary user organisations as co-producers? Res Policy 40(2):242-252. https://doi.org/10. 1016/j.respol.2010.09.006

Boon WPC, Chappin MMH, Perenboom J (2014a) Balancing divergence and convergence in transdisciplinary research teams. Environ Sci Pol 40:57-68. https://doi.org/10.1016/j.envsci.2014.04.005

Boon WPC, Moors EHM, Meijer AJ (2014b) Exploring dynamics and strategies of niche protection. Res Policy 43(4):792-803. https://doi. org/10.1016/j.respol.2014.01.005

Bozeman B, Rogers JD (2002) A churn model of scientific knowledge value: internet researchers as a knowledge value collective. Res Policy 31:769 794. https://doi.org/10.1016/S0048-7333(01)00146-9

Bremer S, Meisch S (2017) Co-production in climate change research: reviewing different perspectives. Wiley Interdiscip Rev Clim Chang 8(6):e482. https://doi.org/10.1002/wcc.482 Wiley-Blackwell

Brouwer S, Büscher C, Hessels LK (2018) Towards transdisciplinarity: a water research programme in transition. Sci Public Policy 45(2):211220 Oxford University Press. https://doi.org/10.1093/scipol/scx058

Brownson RC, Royer C, Ewing R, McBride TD (2006) Researchers and policymakers: travelers in parallel universes. Am J Prev Med 30(2): 164-172. https://doi.org/10.1016/j.amepre.2005.10.004

Brugnach M (2017) The space in between: where multiple ways of knowing in water management meet. J Southwest 59(1-2):34-59 The Southwest Center, University of Arizona. https://doi.org/10.1353/ jsw.2017.0005

Choi BCK, Pak AWP (2006) Multidisciplinarity, interdisciplinarity and transdisciplinarity in health research, services, education and policy: 1. Definitions, objectives, and evidence of effectiveness. Clin Invest Med 29(6):351-364. https://doi.org/10.25011/cim.v30i6.2950

Choi BCK, Pang T, Lin V, Puska P, Sherman G, Goddard M, Ackland MJ et al (2004) Can scientists and policy makers work together? BMJ (Clinical Research Ed) 328(7445):906-907 BMJ Publishing Group Ltd. https://doi.org/10.1136/bmj.328.7445.906

Constant EW (1987) The social locus of technological practice? In: Bijker WE, Hughes TP, Pinch T (eds) The Social Construction of Technological Systems. MIT Press, Cambridge

Cooke-Davies T (2002) The 'real' success factors on projects. Int J Proj Manag 20(3):185-190. https://doi.org/10.1016/S0263-7863(01) 00067-9

de Jong SPL, Wardenaar T, Horlings E (2016) Exploring the promises of transdisciplinary research: a quantitative study of two climate research programmes. Res Policy 45(7):1397-1409. https://doi.org/ 10.1016/j.respol.2016.04.008

de Wit A (1988) Measurement of project success. Int J Proj Manag 6(3): 164-170. https://doi.org/10.1016/0263-7863(88)90043-9

Garud R, Rappa MA (1994) A socio-cognitive model of technology evolution: the case of cochlear implants. Organ Sci 5(3):344 362. https://doi.org/10.1287/orsc.5.3.344
Hegger D, Lamers M, Van Zeijl-Rozema A, Dieperink C (2012a) Conceptualising joint knowledge production in regional climate change adaptation projects: success conditions and levers for action. Environ Sci Pol 18(April):52-65. https://doi.org/10.1016/j.envsci. 2012.01.002

Hegger D, Van Zeijl-Rozema A, Dieperink C (2012b) Toward design principles for joint knowledge production projects: lessons from the deepest polder of The Netherlands. Reg Environ Chang 14(3): 1049-1062 Springer Berlin Heidelberg. https://doi.org/10.1007/ s10113-012-0382-6

Hinkel J, Bisaro A (2016) Methodological choices in solution-oriented adaptation research: a diagnostic framework. Reg Environ Chang 16(1):7-20 Springer Berlin Heidelberg. https://doi.org/10.1007/ s10113-014-0682-0.

Hirsch Hadorn G, Hoffmann-Riem H, Biber-Klemm S, GrossenbacherMansuy W, Joye D, Pohl C, Wiesmann U, Zemp E (2008) Handbook of transdisciplinary research. Springer, Dordrecht

Kates RW (2011) What kind of a science is sustainability science? Proc Natl Acad Sci U S A 108(49):19449-19450 National Academy of Sciences. https://doi.org/10.1073/pnas.1116097108

Kemp R, Schot J, Hoogma R (1998) Regime shifts to sustainability through processes of niche formation: the approach of strategic niche management. Tech Anal Strat Manag 10(2). Routledge): 175-198. https://doi.org/10.1080/09537329808524310.

Kenis P, Provan KG (2009) Towards an exogenous theory of public network performance. Public Adm 87(3). Blackwell Publishing Ltd):440-456. https://doi.org/10.1111/j.1467-9299. 2009.01775.x.

Klenk N, Meehan K (2015) Climate change and transdisciplinary science: problematizing the integration imperative. Environ Sci Pol 54:160 167. https://doi.org/10.1016/j.envsci.2015.05.017

Kloet RR, Hessels LK, Zweekhorst MBM, Broerse JEW, de Cock Buning T (2012) Understanding constraints in the dynamics of a research programme intended as a niche innovation. Sci Public Policy 40(2):206-218. https://doi.org/10.1093/scipol/scs081

Kloet RR, Hessels LK, Zweekhorst MBM, Broerse JEW, de Cock Buning T (2013) Understanding constraints in the dynamics of a research programme intended as a niche innovation. Sci Public Policy 40(2). OUP, New York):206-218. https://doi.org/10.1093/ scipol/scs081.

Lauto G, Sengoku S (2015) Perceived incentives to transdisciplinarity in a Japanese university research center. Futures 65(January). Pergamon):136-149. https://doi.org/10.1016/J.FUTURES.2014.10. 010.

Lemos MC, Kirchhoff CJ, Ramprasad V (2012) Narrowing the climate information usability gap. Nat Clim Chang 2(11). Nature Publishing Group):789-794. https://doi.org/10.1038/nclimate1614

Lyall C, Meagher L, Bruce A (2015) A rose by any other name? Transdisciplinarity in the context of UK research policy. Futures 65(January). Pergamon):150-162. https://doi.org/10.1016/J. FUTURES.2014.08.009.

McNie EC (2007) Reconciling the supply of scientific information with user demands: an analysis of the problem and review of the literature. Environ Sci Pol 10(1):17-38. https://doi.org/10.1016/j.envsci. 2006.10.004

Moss RH, Meehl GA, Lemos MC, Smith JB, Arnold JR, Arnott JC, Behar D et al (2013) Hell and high water: practice-relevant adaptation science. Science 342(6159). https://doi.org/10.1126/science. 1239569

Nelson RR, Winter SG (1982) An evolutionary theory of economic change. Harvard University Press, Cambridge

Nowotny H, Scott P, Gibbons M (2001) Re-thinking science: knowledge and the public in an age of uncertainty. Polity Press, Cambridge

Pohl C, Rist S, Zimmermann A, Fry P, Gurung GS, Schneider F, Speranza CI, Kiteme B, Boillat S, Serrano E, Hadorn GH, Wiesmann U (2010) Researchers' roles in knowledge co-production: experience 
from sustainability research in Kenya, Switzerland, Bolivia and Nepal. Sci Public Policy 37(4):267-281. https://doi.org/10.3152/ $030234210 X 496628$

Provan KG, Milward HB (1999) Do networks really work? A framwork for evaluating public-sector organizational networks. Acad Manag Proc 1999(1). Academy of Management):A1-A6. https://doi.org/ 10.5465/APBPP.1999.27628083

Raven RPJM (2005) Strategic Niche Management for Biomass. Eindhoven University of Technology, Eindhoven

Rosenfield PL (1992) The potential of transdisciplinary research for sustaining and extending linkages between the health and social sciences. Soc Sci Med 35(11):1343-1357. https://doi.org/10.1016/ 0277-9536(92)90038-R

Rosenlund J, Rosell E, Hogland W (2016) Overcoming the triple helix boundaries in an environmental research collaboration. Sci Public Policy 80(2). Högskoleverket, Stockholm):scw045. https://doi.org/ $10.1093 / \mathrm{scipol} / \mathrm{scw} 045$

Runhaar H, Mees H, Wardekker A, Sluijs J, Driessen PPJ (2012) Adaptation to climate change-related risks in Dutch urban areas: stimuli and barriers. Reg Environ Chang 12(4):777-790. https:// doi.org/10.1007/s10113-012-0292-7

Runhaar HAC, Uittenbroek CJ, van Rijswick HFMW, Mees HLP, Driessen PPJ, Gilissen HK (2016) Prepared for climate change? A method for the ex-ante assessment of formal responsibilities for climate adaptation in specific sectors. Reg Environ Chang 16(5). Springer Berlin Heidelberg):1389-1400. https://doi.org/10.1007/ s10113-015-0866-2.

Scarbrough H (2004) Project-based learning and the role of learning boundaries. Organ Stud 25(9):1579-1600. https://doi.org/10.1177/ 0170840604048001

Scholz RW, Steiner G (2015) The real type and ideal type of transdisciplinary processes: part II-what constraints and obstacles do we meet in practice? Sustain Sci 10(4). Springer Japan):653-671. https://doi.org/10.1007/s11625-015-0327-3.

Schot J, Geels FW (2008) Strategic niche management and sustainable innovation journeys: theory, findings, research agenda, and policy. Tech Anal Strat Manag 20(5):537-554. https://doi.org/10.1080/ 09537320802292651
Smith A, Raven R (2012) What is protective space? Reconsidering niches in transitions to sustainability. Res Policy 41(6). Elsevier B.V.): 1025-1036. https://doi.org/10.1016/j.respol.2011.12.012

Smith A, Kern F, Raven R, Verhees B (2013) Spaces for sustainable innovation: solar photovoltaic electricity in the UK. Technological Forecasting and Social Change, no. march 2012 (march). Elsevier Inc. https://doi.org/10.1016/j.techfore.2013.02.001

Stokols D, Misra S, Moser RP, Hall KL, Taylor BK (2008) The ecology of team science: understanding contextual influences on transdisciplinary collaboration. Am J Prev Med 35(2 Suppl):S96-S115. https://doi.org/10.1016/j.amepre.2008.05.003

Ulmanen JH, Verbong GPJ, Raven RPJM (2009) Biofuel developments in Sweden and the Netherlands: protection and socio-technical change in a long-term perspective. Renew Sust Energ Rev 13(6): 1406-1417. https://doi.org/10.1016/j.rser.2008.10.001

Wenger E (1998) Communities of practice: learning, meaning and identity. Cambridge University Press, Cambridge

Whitley R (2000) The intellectual and social organization of the sciences. Oxford University Press, Oxford

Yin RK (2009) Case study research: design and methods. In: Bickman L, Rog DJ (eds) Essential guide to qualitative methods in organizational research, Applied social research methods series, vol 5. Sage publications, Thousand Oaks. https://doi.org/10.1097/FCH. 0b013e31822dda9e

Zscheischler J, Rogga S, Busse M (2017) The adoption and implementation of transdisciplinary research in the field of land-use sciencea comparative case study. Sustainability $9(11)$. Multidisciplinary Digital Publishing Institute: 1926). https://doi.org/10.3390/ su9111926

Publisher's note Springer Nature remains neutral with regard to jurisdictional claims in published maps and institutional affiliations. 